Avicenna Journal of Nursing and Midwifery Care - ISSN 2676-5748

\title{
The Effect of Group Mindfulness-Based Stress Reduction Program on the Quality of Life and Fatigue in Patients With Multiple Sclerosis
}

\author{
Mercedeh Ghazagh $^{1^{*}}$, Zohreh Zadhasan ${ }^{2}$ \\ 1. MA, Department of Psychology, Faculty of Psychology, Payame NourUniversity, Tehran, Iran \\ 2. MA, Department of Psychology, Faculty of Psychology, Ahvaz Branch, Islamic Azad University, Ahvaz, \\ Iran
}

Article Info $\quad$ Abstract

Received: $\quad 2018 / 05 / 08$

Accepted: $\quad 2018 / 05 / 27$

Published Online: 2019/03/22

DOI: $10.30699 /$ ajnmc.27.1.35

Original Article

Use your device to scan and read the article online

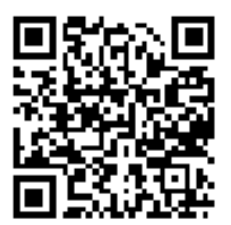

Introduction: Multiple Sclerosis (MS) is considered to be one of the most common chronic diseases of the central nervous system. Its chronic nature, no cure being available and its onset at a young age can have a devastating effect on quality of life and fatigue. This research aims to study the effect of group mindfulness-based stress reduction program and conscious yoga on the quality of life and fatigue in patients with Multiple Sclerosis.

Methods: This was a quasi-experimental study with pretest-posttest design and control group. The sampling method was initially a public call amogst members of the MS Society in Tehran. 24 patients with MS and having the criteria needed for inclusion of the applicants were randomly assigned to the experimental group $(n=12)$ and control group $(\mathrm{n}=12)$. The participants completed MS patients' Quality of Life questionnaires (MSQOL-54) and the Fatigue Severity Scale (FSS), before and after treatment. The experimental group was treated in 8 sessions of group mindfulness-based stress reduction program (for 2 hours each session). Data was analyzed using covariance single variable and SPSS 21.

Results: The results showed that there was a significant difference amogst the mean scores of some subscales of the quality of life including physical functioning, role in relation to physical and mental energy, mental well-being, health threats, perceived health, satisfaction with sexual function, quality of life and fatigue test and control groups $(P<0.05)$.

Conclusion: The results showed that the program of reduction of consciousness-based stress is effective in reducing fatigue and increasing some of the subscales of quality of life in MS patients. Therefore, it can be concluded that if such interventions are applied to patients with chronic illnesses such as MS in addition to medical therapies, their illness can be reduced by changing perceptions of patients from their long-term illness.

Keywords: Multiple Sclerosis, Fatigue, Quality of Life, Mindfulness-Based Stress Reduction Program

Copyright $(C)$ 2019, This is an original open-access article distributed under the terms of the Creative Commons Attribution-noncommercial 4.0 International License which permits copy and redistribute of the material just in noncommercial usages with proper citation. 
مجلة مراقبت يرستارى و مامايى ابنسينا - شايا الكترونيك: UVY-DVA

مقالل يزوهشى

اثربخشى برنامهُ كاهش استرس مبتنى بر ذهن آكَاهى به شيوهُ َروهى بر كيفيت زندَّى و شدت خستكى زنان

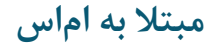

مرسده قزاق'"، زهره زادحسن

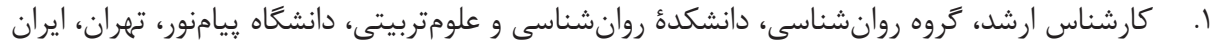

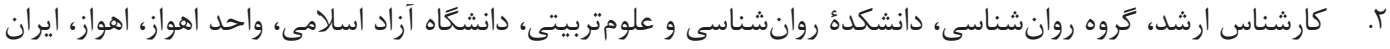

\footnotetext{
جكيده

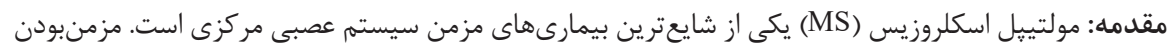

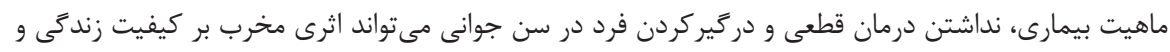

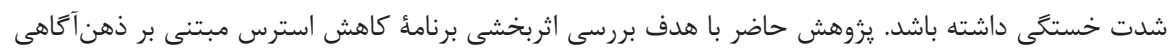

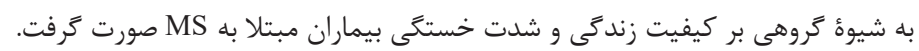

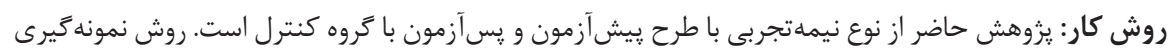

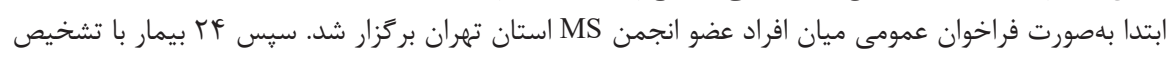

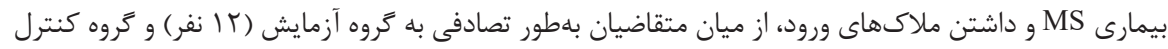

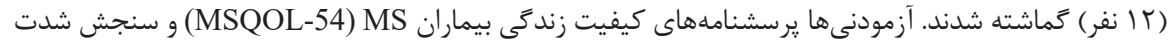

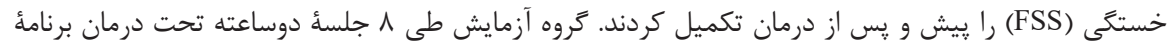

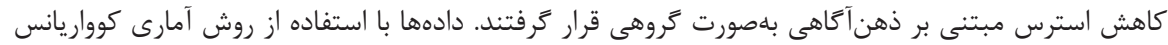

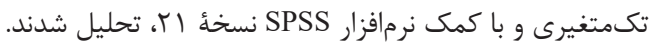
يافتهها: يافتهاى يروهش نشان مىدهد بين ميانكَين نمرات برخى از زيرمقياسهاى كيفيت زندكى شامل

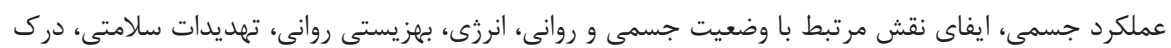

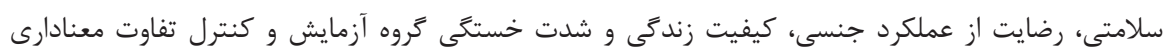

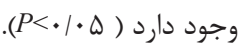

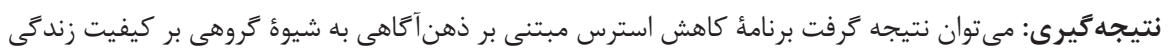

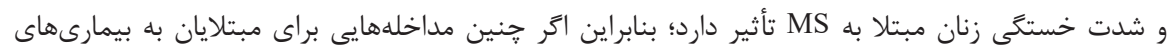

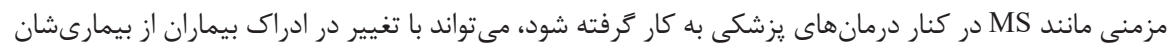
در بلندمدت، شدت بيمارى آنها را كاهش دهان دهد.

كليدوازهها: MS، شدت خستخى، كيفيت زندگى، برنامة كاهش استرس مبتنى بر ذهن آكاهى
}

اطلاعات مقاله - اله

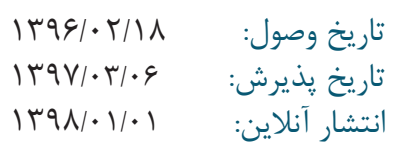

تاريخ وصول: : تاريخ

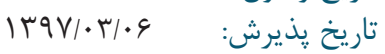

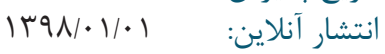

يست الكترونيك:

mercedeh.gh@gmail.com
اين بيمارى معمولاً همزمان با رويارويى با موقعيتهايى مانند

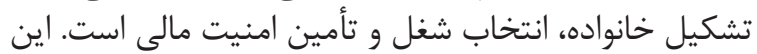

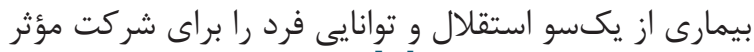

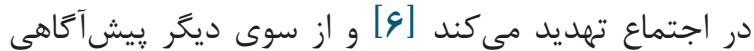

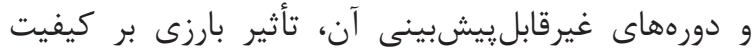

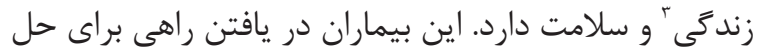

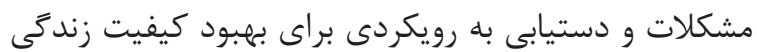

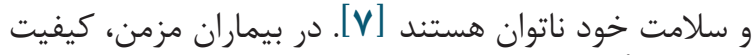

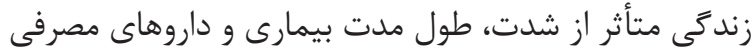

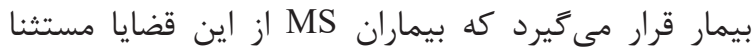

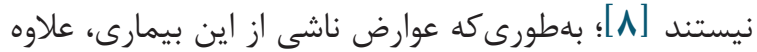

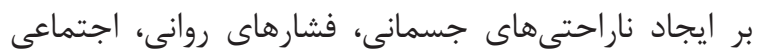

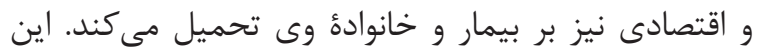

3. Quality of life

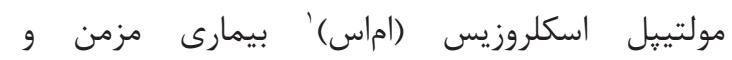

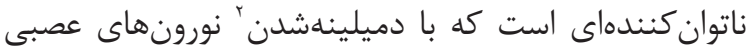

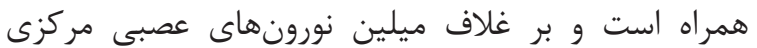

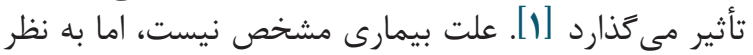

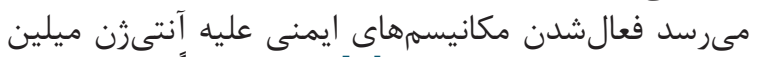

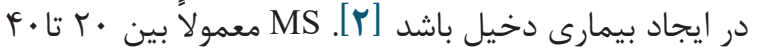

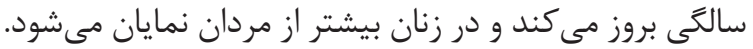

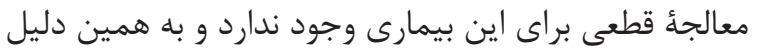

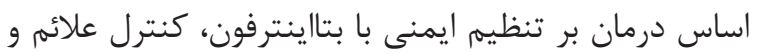

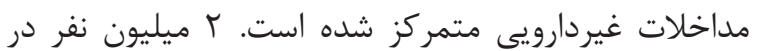

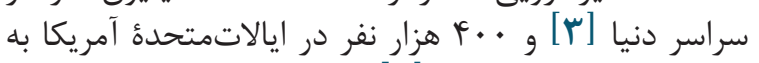

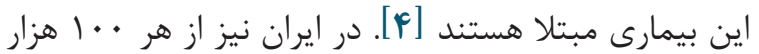

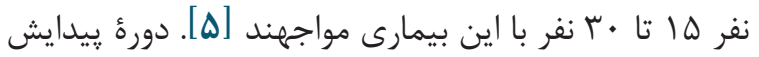

1. Multiple Sclerosis (MS)

2. Damiline 


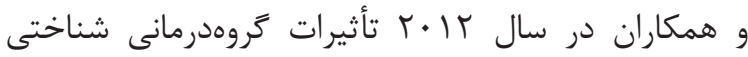

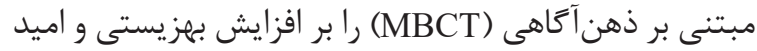

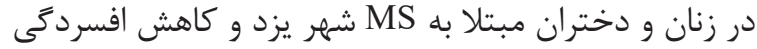

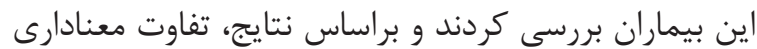

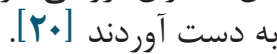

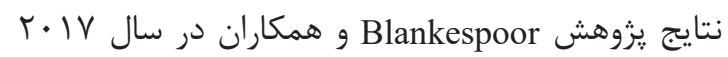

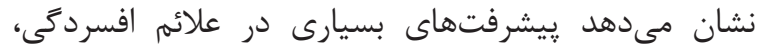

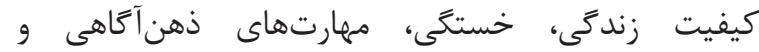

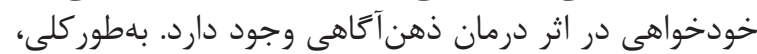

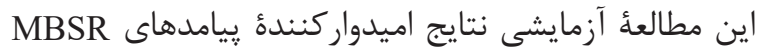

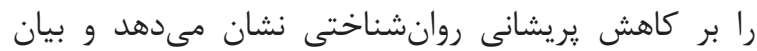

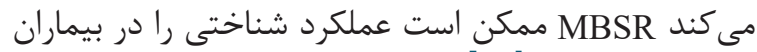

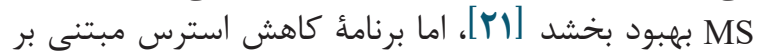

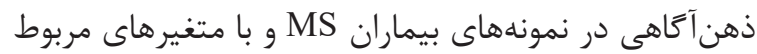

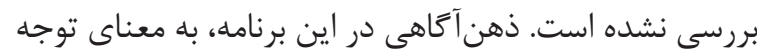

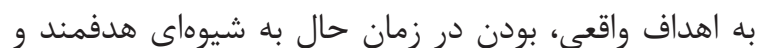

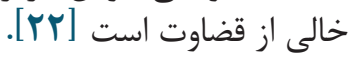

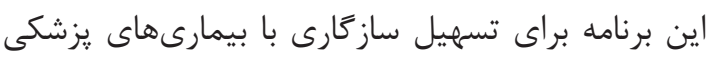

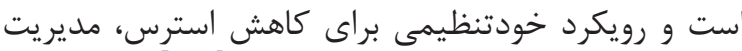

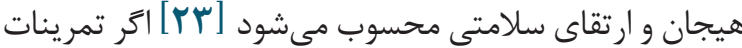

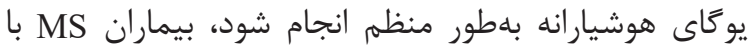

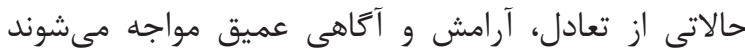
شب[F]

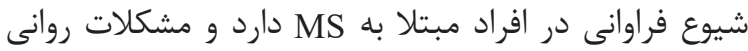

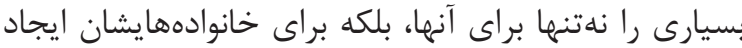

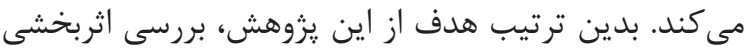

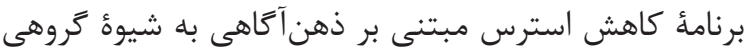

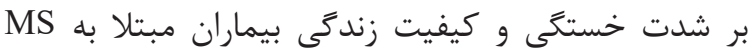

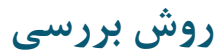

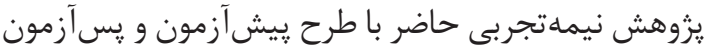

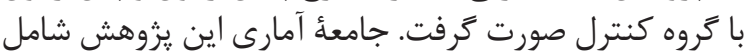

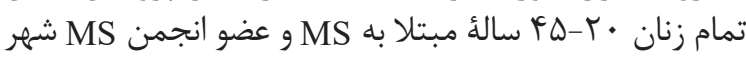

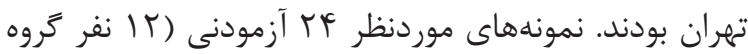

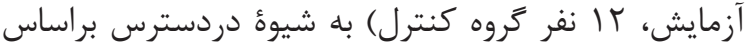

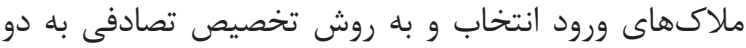

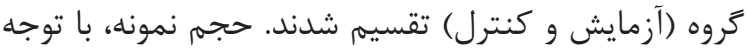

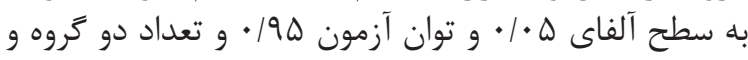

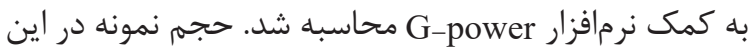

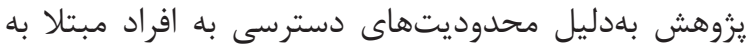

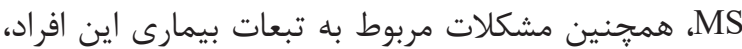

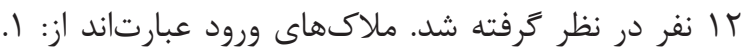

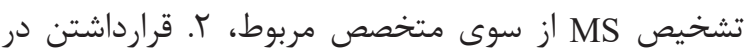

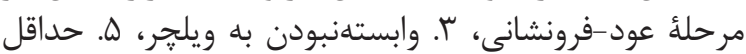

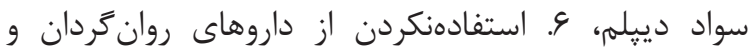

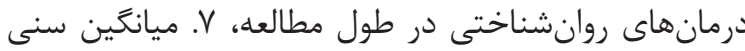

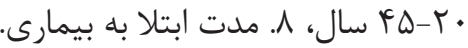

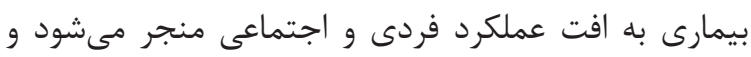

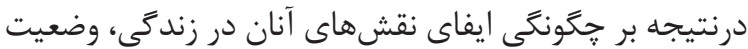

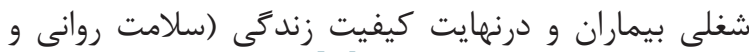

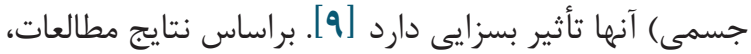

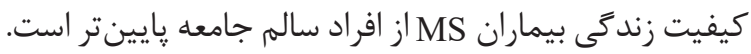

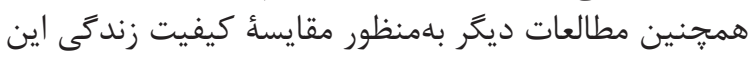

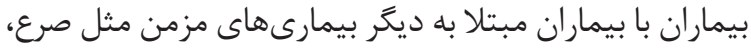

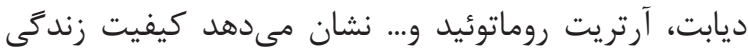

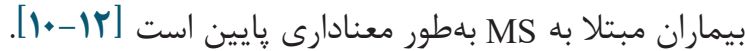

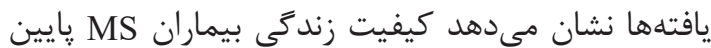

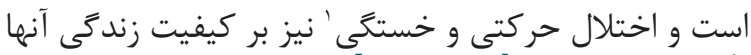

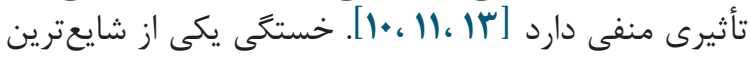

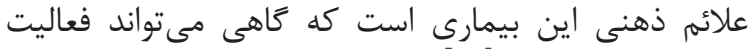

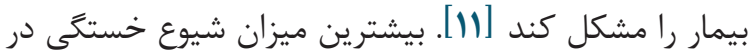

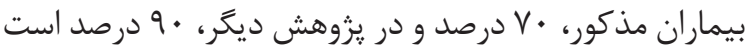

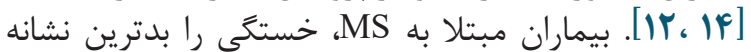

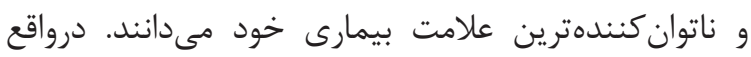

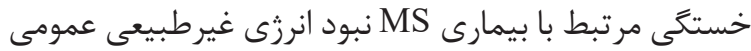

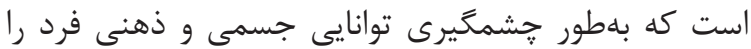

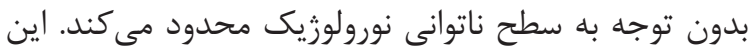

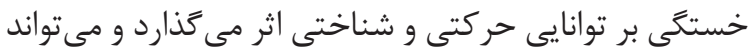

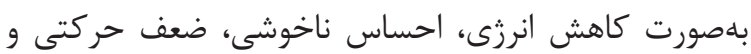

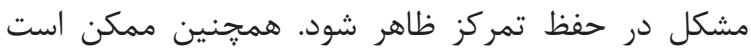

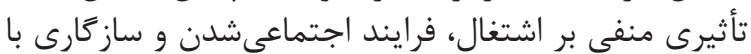

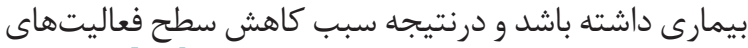

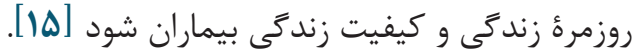

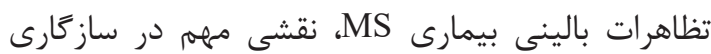

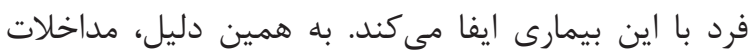

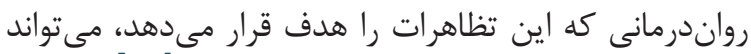

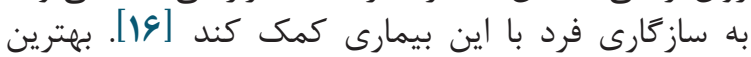

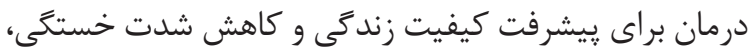

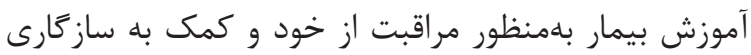

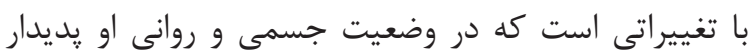

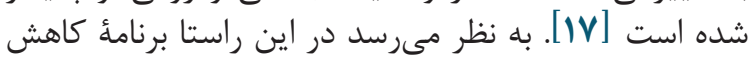

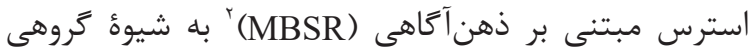

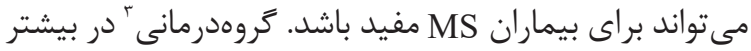

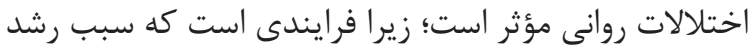

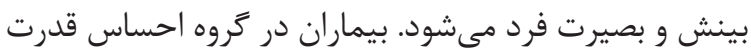

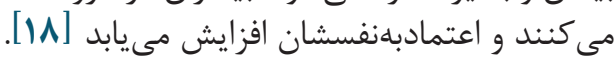

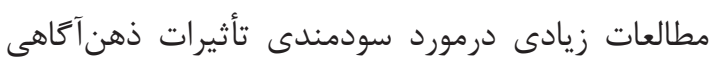

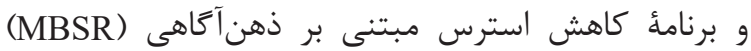

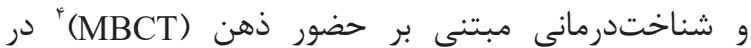

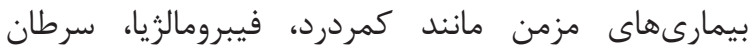

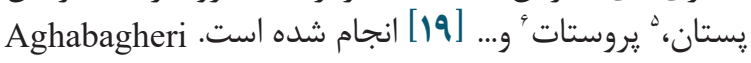

1. Fatigue

2. Mindfulness-Based Stress Reduction (MBSR)

3. Group therapy

4. Mindfulness-Based Cognitive Therapy (MBCT)

5. Breast cancer

6. Prostate cancer 
1ץ اثربخشى برنامة كاهش استرس مبتنى بر ذهن آكاهى ...

تعيين شدهاند. داراى دو نمرة اصلى (نمرءٔ ابعاد جسمانى

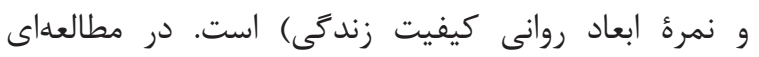

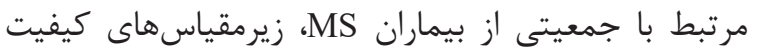

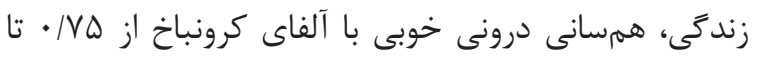

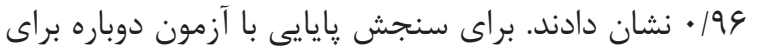

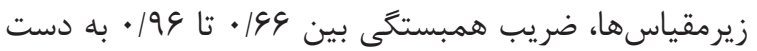

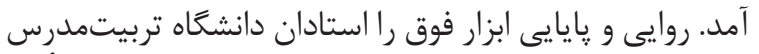

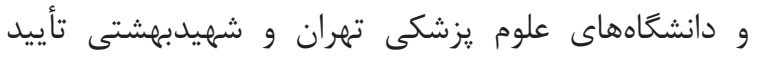

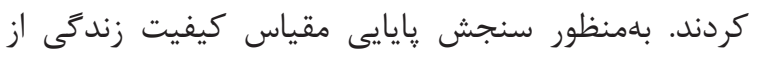

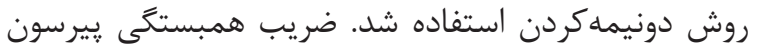

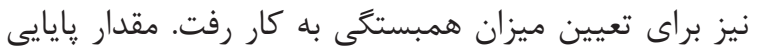

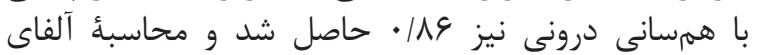

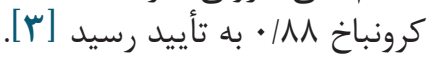

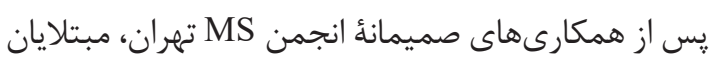

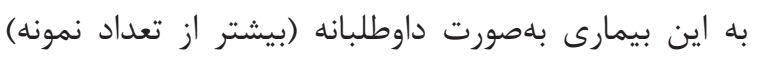

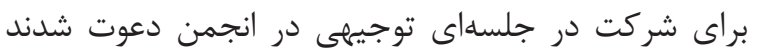

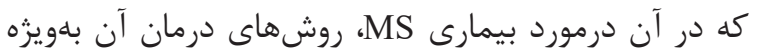

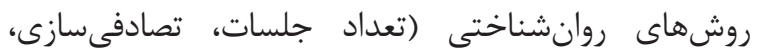

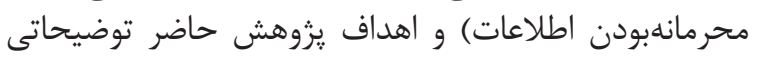

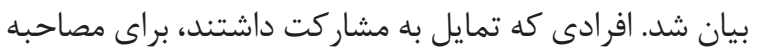

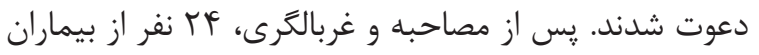

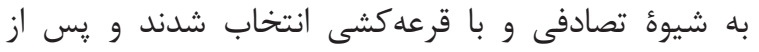

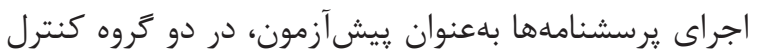

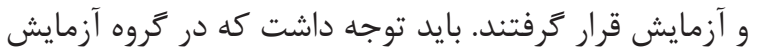

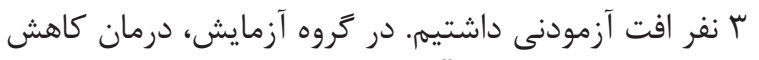

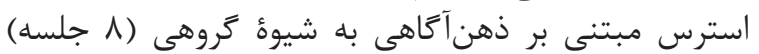

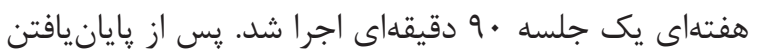

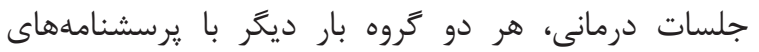

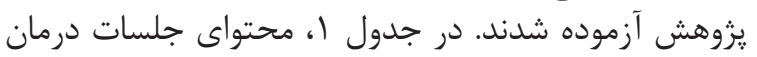

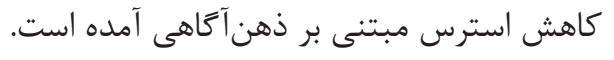

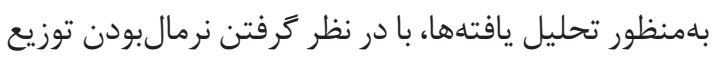

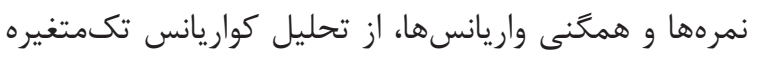
استفاده شد و دادها نيز به به كمك نرمافزار

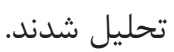

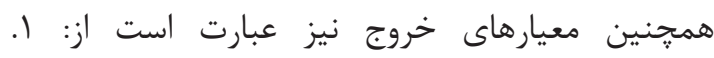

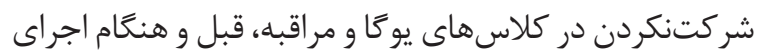

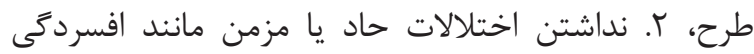

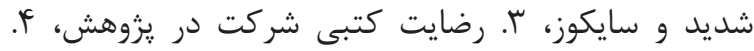
غيبت بيش از دو جلسه در فرايند طرح درمان.

ملاحظات اخلاقى يزوهش حاضر به شرح زير است:

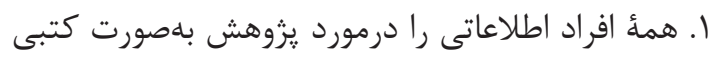

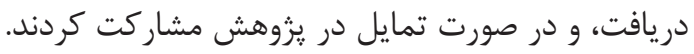

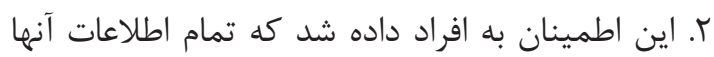

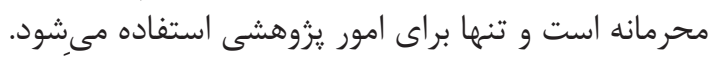

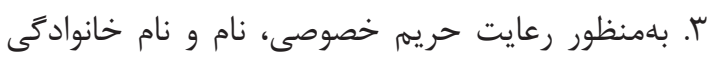
شركت كنندكان ثبت نشد.

\section{ابزارهاى ترد آورى اطلاعات \\ مقياس شدت خستكى (FSS) (ئ)}

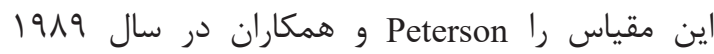

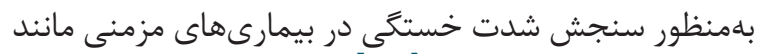
MS

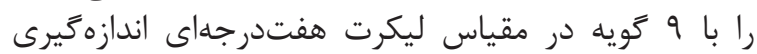

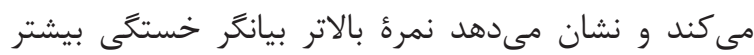

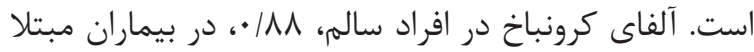

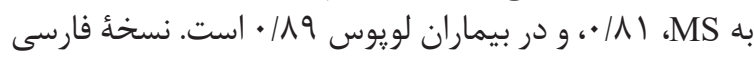

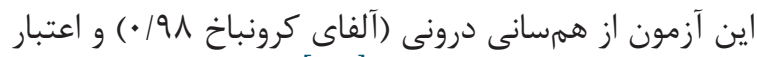

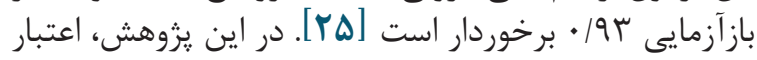

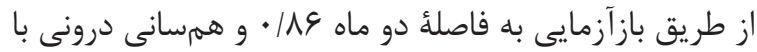

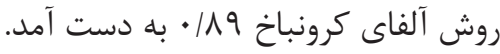

كيفيت زندكى بيماران مولتييل اسكلروزيس

( $(\Delta F-M S Q O L)$

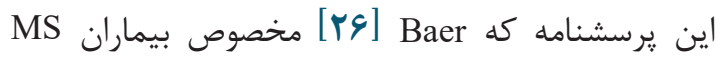

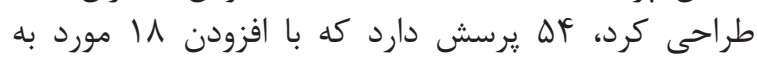

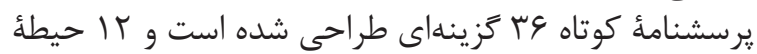

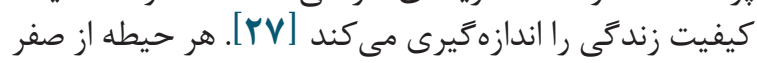

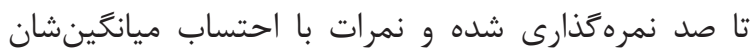

جدول ا. خلاصُٔ دستور العمل اجرايى جلسات برنامهٔ كاهش استرس مبتنى بر ذهن آكاهى

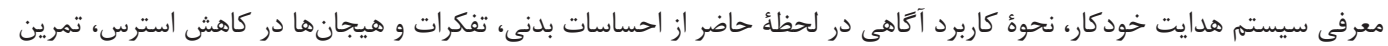

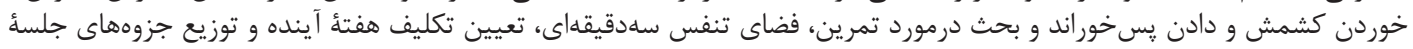
اول و سى سىى مراقبه تنفا

تمرين مجدد وارسى بدن، دادن پِخوراند و بحث درمورد تمرين وارسى بدن، تمرين مراقبهُ ذهن آحاهى تنفس، تمرين كششى يوَا، توزيع

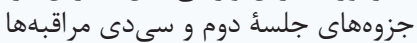

نشست هوشيارانه با آكاهى از تنفس (مراقبهُ نشسته)، تمرينهاى يوگا، تمرين فضاى تنفس سهدقيقهاى، توزيع جزوات جلسأ سوم و نوار مربوط به حركات يوكا تمرين

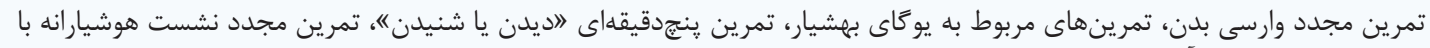

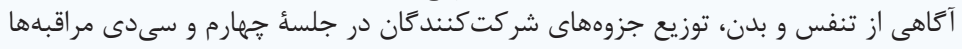

קهارم 


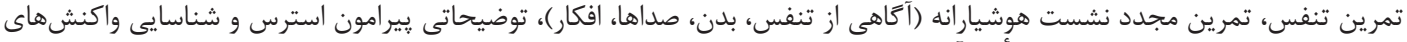

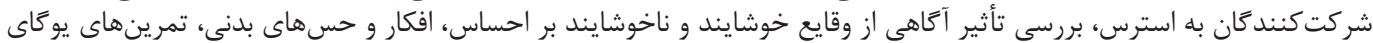

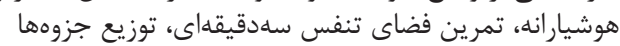

انجامدادن يوكاى هوشيارانه، مراقبئ نشسته (حضور ذهن از صداها و افكار)، توزيع جزوههاى جلسؤ و و نوار شماره f ميان شركت كنندكان مراقبئ كوهستان، بهداشت خواب، تكرار تمرينهاى جلسههاى قبل، تهيئ فهرستى از فعاليتهاى لذتبخش، توزيع جزوههاى جلسهُ هفتم تمرين وارسى بدن، بازنگرى كل برنامه، وارسى و بحث درمورد برنامهها، انجام مراقبئ سنگ، مهره و تيله، اجراى پِسآزمون

با توجه به جدول "ا، پيشفرض تساوى واريانسها در هر دو مرحله تأييد شده است.

با توجه به جدول أل، نتايج تحليل كواريانس تكمتغيرى آنارى

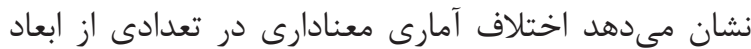
كيفيت زند

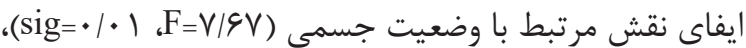
ايفاى نقش مرتبط با وضعيت روانى (

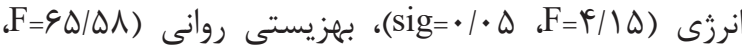

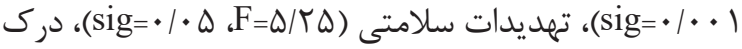

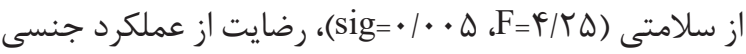

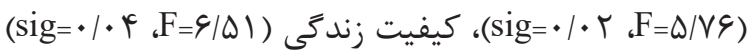

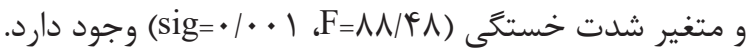

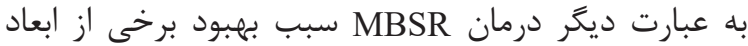

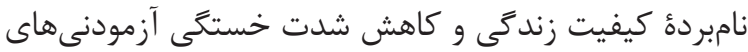

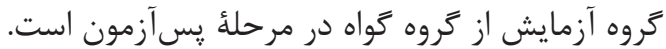

محاسبء ميانخين و انحراف معيار با استفاده از آمار

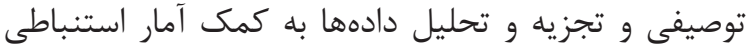

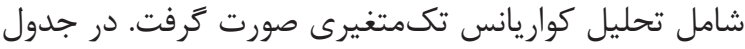

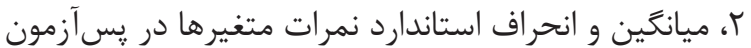

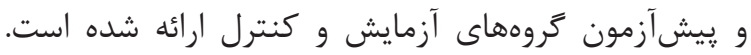

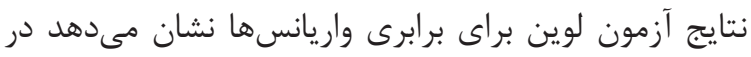

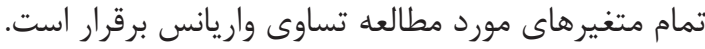
با توجه به جدول r ب، ميانگين شدت خستخى در گروه

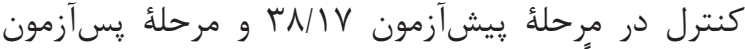

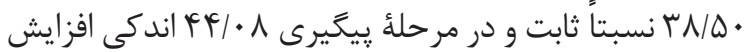

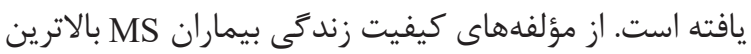

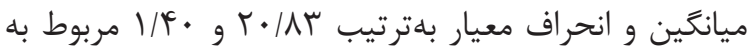

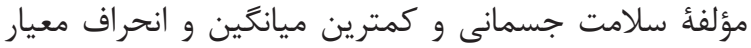

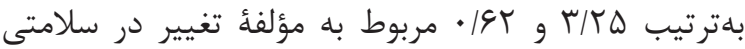

جدول r. ميانغين و انحراف معيار متغيرهاى يزوهش در تروه كنترل

\begin{tabular}{|c|c|c|c|c|}
\hline يَيَيرى & يس آزمون & بيش آزمون & كروهها & متغير \\
\hline$|\psi| / \cdot \Lambda$ & rN/D. & rN/IV & ميانَين & \multirow{2}{*}{ شدت خستخى } \\
\hline$p / r$. & $F / T)$ & F/Tr & انحراف معيار & \\
\hline$r \cdot \mid \Lambda r$ & $r \cdot \mid \Lambda r$ & $r \cdot$ & ميانغين & \multirow{2}{*}{ سلامت جسمى } \\
\hline $1 / \Delta T$ & $1 / 4$. & $r / r q$ & انحراف معيار & \\
\hline سس/ه & F/ar & $F / 9 V$ & ميانغَين & \multirow{2}{*}{ ايفاى نقش مرتبط با مشكل جسمى } \\
\hline $1 / 10$ & $\cdot / v 9$ & .191 & انحراف معيار & \\
\hline$q / 4 T$ & $1 \cdot 1 \cdot 1$ & $11 / \cdot \wedge$ & ميانغَين & \multirow[b]{2}{*}{ درد } \\
\hline $1 / \Delta$. & $1 / \pi V$ & $1 / \Delta$ & انحراف معيار & \\
\hline $19 / \cdot 1$ & I $18 / \wedge r$ & $19 / \cdot 1$ & ميانگين & \multirow{2}{*}{ انرزى } \\
\hline $1 / k F$ & $1 / \Lambda$. & $1 / 94$ & انحراف معيار & \\
\hline$I V / T \Delta$ & 19/Ar & $\mid \Delta / V \Delta$ & ميانَين & \multirow{2}{*}{ ادراكات سلامتى } \\
\hline$T / T V$ & $1 / 99$ & $1 / 90$ & انحراف معيار & \\
\hline$\Delta / \Delta V$ & $\Delta / \Delta V$ & $9 / 0$. & ميانَين & \multirow{2}{*}{ عملكرد جنسى } \\
\hline $1 / \pi 1$ & $1 / \pi 1$ & $r / \cdot r$ & انحراف معيار & \\
\hline
\end{tabular}




\begin{tabular}{|c|c|c|c|c|}
\hline بيخَيرى & يس آزمون & ييش آزمون & ترومها & متغير \\
\hline$\Lambda / \Delta \Lambda$ & $V / G V$ & V/AT & ميانگَين & \multirow{2}{*}{ عملكرد اجتماعى } \\
\hline $1 / 19$ & $1 / \pi r$ &.$/ 9$. & انحر اف معيار & \\
\hline س س/ه & r/qr & $F / 9 V$ & ميانگين & \multirow[b]{2}{*}{ ايفاى نقش مرتبط با مشكل روانى } \\
\hline $1 / 10$ & $\cdot / \vee 9$ &.$/ 91$ & انحراف معيار & \\
\hline$|N| \cdot$ & $|N| \cdot$ & $1919 \mathrm{~V}$ & ميانگين & \multirow{2}{*}{ 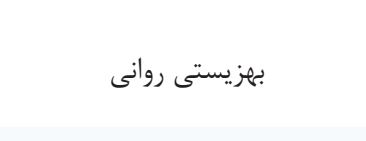 } \\
\hline $1 / \Lambda$. & $|/ 4|$ & $r / \cdot 1$ & انحراف معيار & \\
\hline $\mid r / T \Delta$ & $\mid r / r \Delta$ & Ir & ميانگَين & \multirow{2}{*}{ عملكرد شناختى } \\
\hline .199 & .199 & $1 / V$ & انحر اف معيار & \\
\hline $1 \cdot 11 \mathrm{~V}$ & $1 . / 1 \mathrm{~V}$ & N/9T & ميانگين & \multirow{2}{*}{ 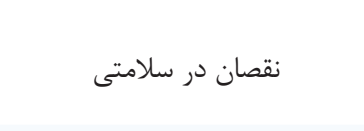 } \\
\hline $1 / 4$. & $1 / 19$ & $1 / \Delta 9$ & انحراف معيار & \\
\hline $9 / 9 V$ & ه/A & $\Delta / / V$ & ميانكين & \multirow{2}{*}{ رضايت از زندىى } \\
\hline $1 / 9 \mathrm{~V}$ & $19 / 94$ & $1 / \Delta T$ & انحراف معيار & \\
\hline T/KT & T/FT & $r / T \Delta$ & ميانكَين & \multirow{2}{*}{ تغيير در سلامتى } \\
\hline$\cdot|\Delta|$ & $\cdot|\Delta|$ & .194 & انحراف معيار & \\
\hline T/VQ & $T / V \Delta$ & $r / T \Delta$ & ميانگَين & \multirow{2}{*}{ رضايت از عملكرد جنسى } \\
\hline$\cdot / V \Delta$ & $\cdot / V \Delta$ & $1 / 1 \pi$ & انحراف معيار & \\
\hline
\end{tabular}

جدول ب. نتايج آزمون لون بلمنظور بررسى پيشفرض همسانى واريانسها در متغير كيفيت زندكى و شدت خستكى بيماران

متغير

\begin{tabular}{|c|c|c|c|c|}
\hline ( & TT & 1 & $r / \mathcal{F}$. & سلامت جسمى \\
\hline .1194 & tr & 1 & $1 / 1 / 4$ & ايفاى نقش مرتبط با مشكل جسمى \\
\hline$\cdot 1 \cdot 14$ & rt & 1 & $V / \Delta T \Delta$ & 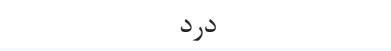 \\
\hline$\cdot / V T \Lambda$ & TT & 1 & $\cdot / M F$ & 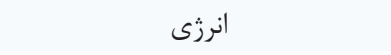 \\
\hline$\cdot / 1 \Delta \varphi$ & rt & 1 & $r / \backslash \Delta \Delta$ & ادراكات سلامتى \\
\hline$\cdot \mid$ ATI & tr & 1 & . IGFT & عملكرد جنسى \\
\hline$\cdot / 499$ & tr & 1 & $1 / 1 F V$ & عملكرد اجتماعى \\
\hline .1194 & rt & 1 & I/A IT & ايفاى نقش مرتبط با مشكل روانى \\
\hline$\cdot / T 94$ & TY & 1 & $1 / \pi \cdot \Delta$ & بهزيستى روانى \\
\hline$\cdot / \cdot \operatorname{ct}$ & tr & 1 & $F / \varphi \Delta F$ & عملكرد شناختى \\
\hline 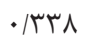 & TT & 1 & .1991 & نقصان در سلامتى \\
\hline - IATV & TT & 1 & $.1 \cdot 4 q$ & رضايت از زندكى \\
\hline $1 / \cdots$ & TT & 1 & $\cdot 1 \cdot \cdot 1$ & تغيير در سلامتى \\
\hline.$/ 1 \mathrm{FT}$ & TT & 1 & $r / T / D$ & رضايت از عملكرد جنسى \\
\hline$\cdot / r \cdot 1$ & TT & 1 & I/VMY & شدت خستخى \\
\hline
\end{tabular}


قزاق و زادحسن

جدول F. مقايسُٔ ميانكَين كيفيت زندكى، خردهمقياسها و شدت خستكى در كروه آزمايش با كنترل براساس آزمون تحليل كواريانس

\begin{tabular}{|c|c|c|c|c|c|c|c|c|c|c|c|}
\hline \multirow[b]{3}{*}{ Eta } & \multirow[b]{3}{*}{ Sig } & \multirow[b]{3}{*}{$\mathrm{F}$} & \multicolumn{4}{|c|}{ آزمايش (r) (n) } & \multicolumn{4}{|c|}{ كنترل (Y=|r) } & \multirow{3}{*}{ كَروهاى آزمايش و كنترل } \\
\hline & & & \multicolumn{2}{|c|}{ يس آزمون } & \multicolumn{2}{|c|}{ يِيش آزمون } & \multicolumn{2}{|c|}{ يسآزمون } & \multicolumn{2}{|c|}{ ييش آزمون } & \\
\hline & & & انحراف & ميانكَين & انحراف & ميانگين & معيار & ميانكَين & انحراف & ميانگَين & \\
\hline$\cdot / 4 \Delta$ & $\cdot 1 \cdot \cdot 1$ & $|\varepsilon / 4|$ & $F / 90$ & N N/r & $\Delta / V q$ & $\Lambda \cdot / r$ & $19 / 11$ & $9 r / 01$ & $\mid \omega / 10$ & $q \cdot / k r$ & عملكرد جسمى \\
\hline •/ $/ \mathrm{V}$ & $\cdot 1 \cdot 1$ & $V / \& V$ & TV/Tr & $\Lambda \Lambda / \Delta \Lambda$ & $T F / F D$ & VN/GI & $\mid F / \Lambda \Lambda$ & $\wedge \mu /$. & $\| r / F \Delta$ & $\wedge \varepsilon / \cdot 9$ & نقش دروديت مشكلات \\
\hline$\cdot \mid 9 F$ & $\cdot 1 \cdot \cdot 1$ & rd/s & $1 \cdot / 4 q$ & $r q / .$. & $10 / 9$. & $\mathrm{Fr} / \cdot \mathrm{G}$ & $r V / \cdot V$ & $\forall \wedge / \cdot \varphi$ & $r \Delta / r$. & FV/AT & نقش دحدوديت ايفاى \\
\hline$\cdot / 14$ & $\cdot / 1$ & $r / q$. & $1 \cdot 1 \wedge \Delta$ & $q r / .$. & $1 \cdot / V r$ & $99 / 71$ & FT/TH & $\Delta ৭ / \wedge \Delta$ & $r / \cdot r$ & $9 \cdot|0|$ & درد \\
\hline •/VG & $\cdot 1 \cdot \cdot 1$ & $\varepsilon \Delta / \Delta \Lambda$ & $\varepsilon / r V$ & $\Delta \Delta / \Delta T$ & $1 \cdot / 4 \lambda$ & $r q / T \Delta$ & $I T / F F$ & $V H / F G$ & $\mid r / \Delta G$ & $V F / \Lambda I$ & بهزيستى روانى \\
\hline$\cdot / 11$ & $\cdot 1 \cdot \Delta$ & $\varphi / 1 \Delta$ & $r q / \Delta \Delta$ & qr/vG & rN/VF & $\vee q / / F$ & $r|q|$ & GN/G. & Q & $99 / \Delta \Delta$ & انرزى \\
\hline$\cdot / 1 \mathrm{~V}$ & $\cdot / \cdot \Delta$ & $F / r \Delta$ & N/Fr & rN/ץ. & V/TK & (1/199 & $\varepsilon|9|$ & $|F| q \mid$ & $V / 4 q$ & $F V / \Lambda$. & درى سلامت \\
\hline$\cdot 1 \cdot 1$ & $\cdot 1 \cdot \wedge$ & $.1 \cdot t$ & $4 / 98$ & $F F / \cdot r$ & $\varphi / \wedge \varepsilon$ & FF/FT & $r / l e$ & rו/.. & $\Delta / T M$ & 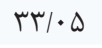 & عملكرد اجتماعى \\
\hline$\cdot 1 \cdot 1$ & .199 & $\cdot 119$ & $V / \Delta F$ & $r \cdot / \Lambda$. & $\varepsilon / \pi \Delta$ & $r / / \cdot r$ & $\Lambda / r)$ & r r & $1 \cdot 1 \cdot 1$ & 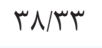 & تغيير سلامتى \\
\hline • $/ T T$ & $\cdot 1 \cdot r$ & $\Delta / \Lambda r$ & $\Lambda / r \Lambda$ & $\uparrow \& / 9$. & $I T / T F$ & $r \cdot 109$ & $\Delta / T V$ & $r \Delta / 1$. & V/VT & $r \varepsilon / 10$ & عملكرد جنسى \\
\hline$\cdot 101$ & $\cdot 1 \cdot \cdot 1$ & $r 1 / \cdot 9$ & $1 / \Delta \Lambda$ & $T T / T V$ & $r / \cdot \Delta$ & $19 / 09$ & $1 / 9 \mu$ & $r \wedge / T I$ & $r / 11$ & $r V / \cdot q$ & عملكرد شناختى \\
\hline • &.$/ \cdot r$ & $\Delta / V \varphi$ & $|r /|$ & $r \cdot / r \Delta$ & $r \cdot / r$. & $r \Delta / F_{\Lambda}$ & $1 N / 48$ & $\mid \dot{Q} / \cdot \cdot$ & $\mid \varepsilon / 94$ & $F F / \cdot V$ & رضايت از عملكرد \\
\hline$\cdot \pi \cdot$ & $\cdot 1 \cdot \Delta$ & $\Delta / r \Delta$ & $r T / Q$. & $4 \cdot|4|$ & $r N / \cdot \Delta$ & $\Delta \varphi / \cdot V$ & $T / \Delta V$ & $\Delta \cdot 19 \Delta$ & $\Delta / \cdot V$ & $\Delta r / I I$ & تهديدات سلامتى \\
\hline - Kt & $.1 \cdot F$ & $9|0|$ & $91 \cdot 9$ & $9 \Delta / \mu r$ & $11 / r \Lambda$ & $91 / 1$. & V/OT & $\Delta \varepsilon / \cdot{ }^{F}$ & $1 / 9 \mathrm{~V}$ & $\Delta \Delta / \cdot 1$ & كيفيت زندكى \\
\hline$\cdot / 4 \wedge$ & $\cdot 1 \cdot \cdot 1$ & $F N / A \Lambda$ & IT/AV & $r q / \cdot 1$ & $r T / \Lambda \Lambda$ & ET/.T & $M F / D I$ & $\Delta \cdot 19$. & $M F / Q$. & $\mathrm{rq} / \mathrm{AV}$ & شدت خستكى \\
\hline
\end{tabular}

$$
\text { در اين بيماران مىشود. }
$$

بحث

در ابعاد ديخر، بهويزه عملكرد اجتماعى، تغيير سلامتى و

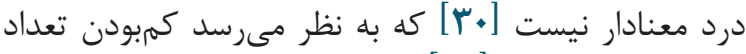

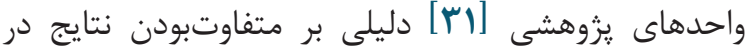

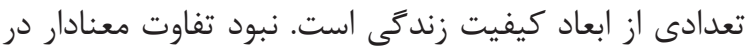

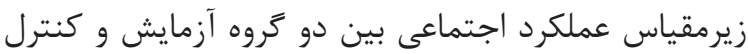

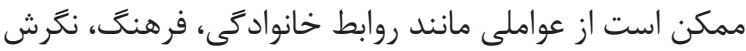

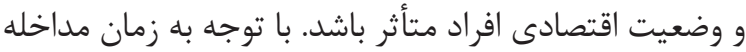

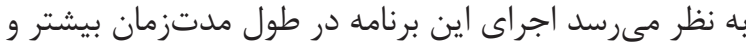

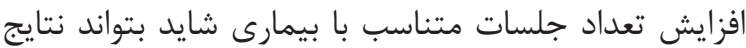

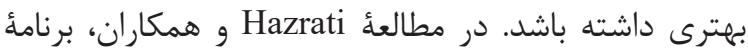

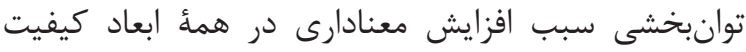

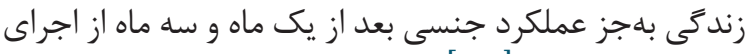

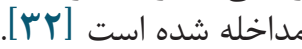
بايد توجه داشت كه بيمارىهاى مزمنى مانند MS دران قطعى ندارند. عوارض ناشى از اين بيمارى نيز به داشي افت عملكرد ماند

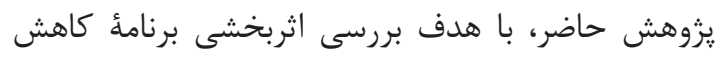

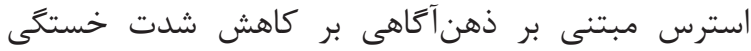

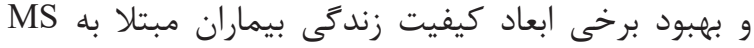

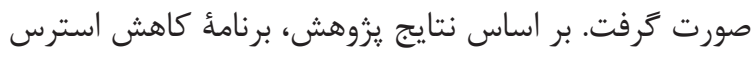

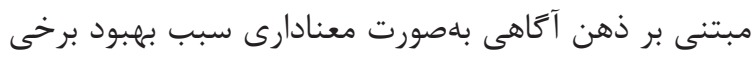

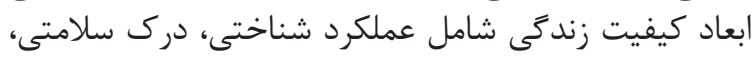

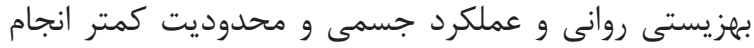

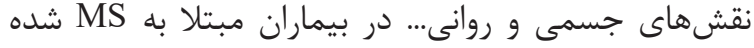

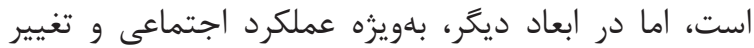

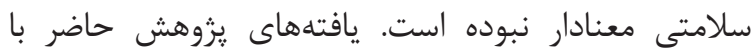

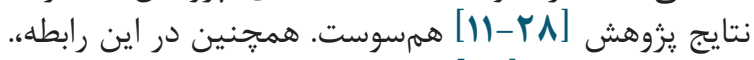

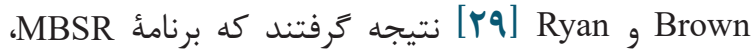

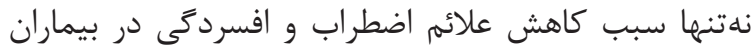

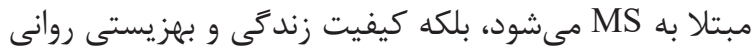

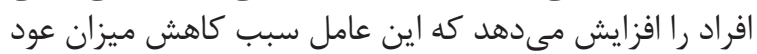




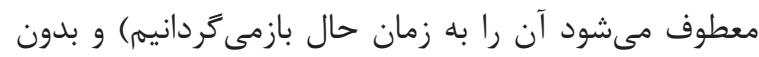

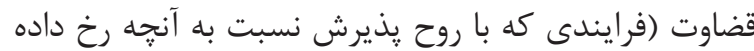

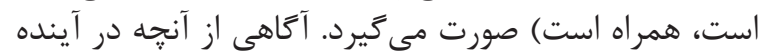

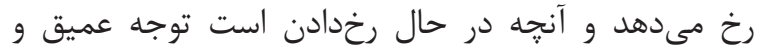

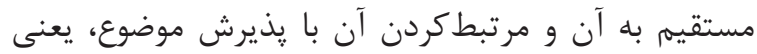

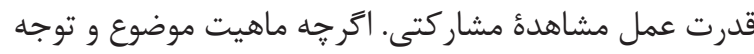

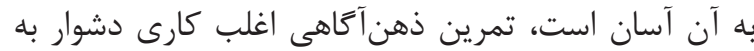

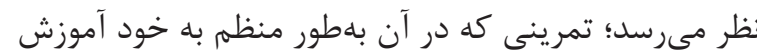

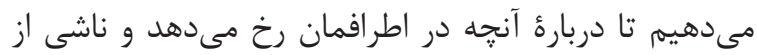

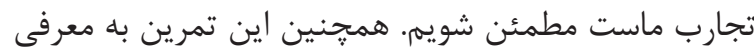

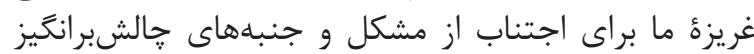

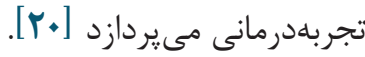

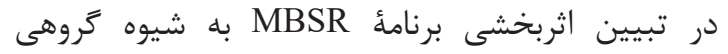

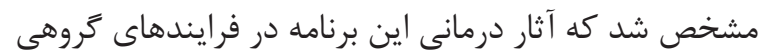

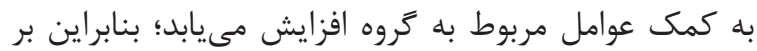

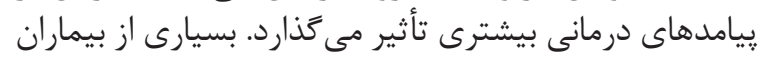

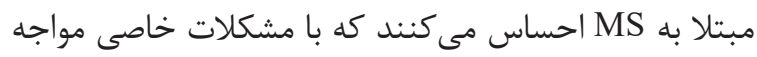

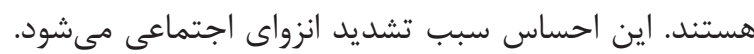

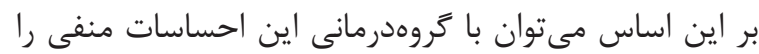

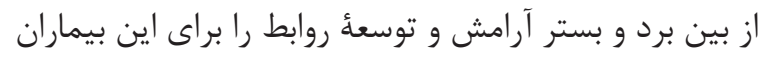

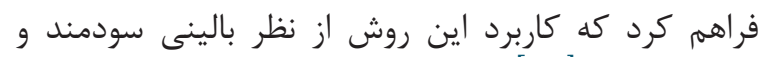

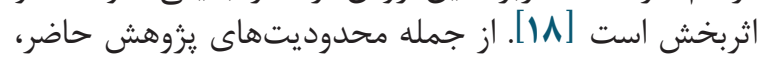

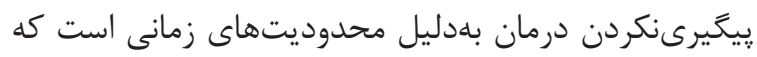

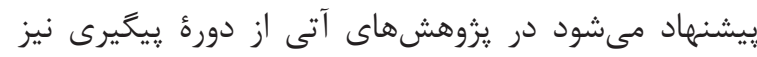
براى ارزيابى تداوم نتايج درمان استفاده شود.

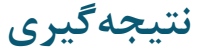

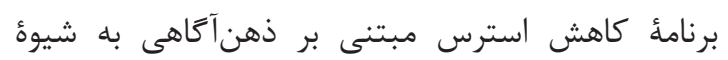

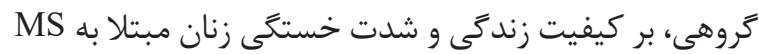

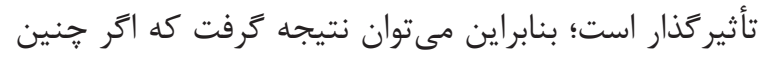

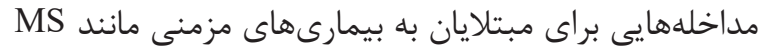

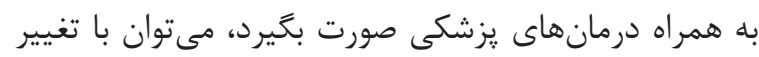

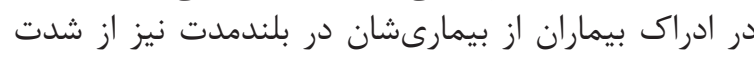

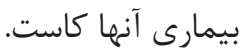

\section{سياسگَزارى}

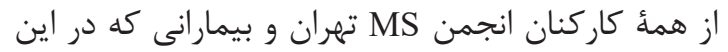

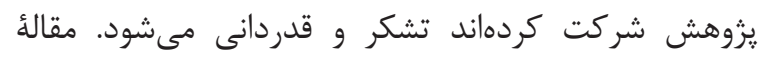

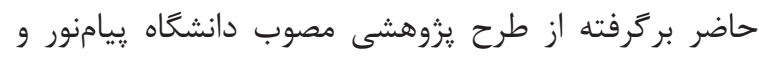
داراى كد كميتةٔ اخلاق

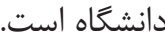

\section{تعارض در منافع}

نويسندَان هيجَّونه تعارضى در منافع ندارند.
فرد منجر مىشود و بر كيفيت زندكى اين بيماران بسيار

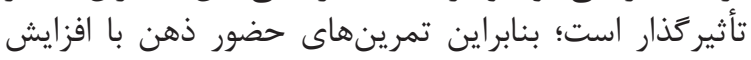

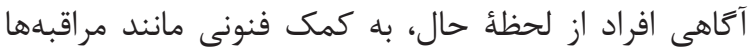

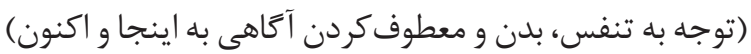

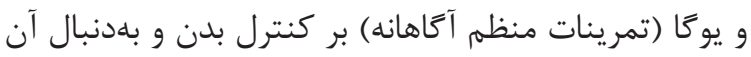

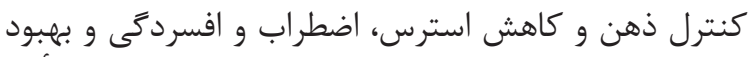

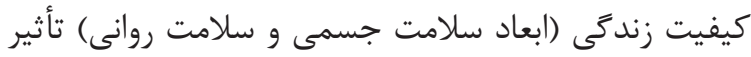

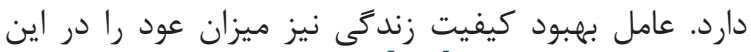

بيماران كاهش مى دهد [برد

درواقع، مداخلأ MBSR به شيؤ كروهى سبب افزايش

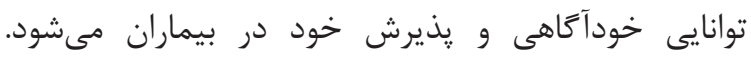

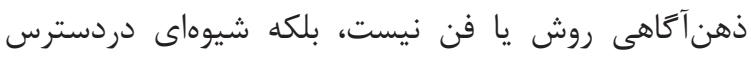

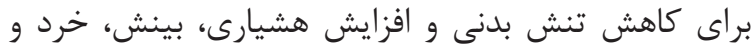

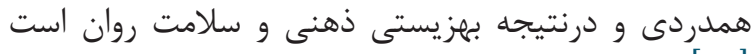

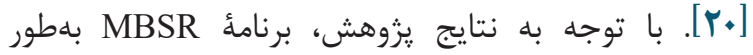

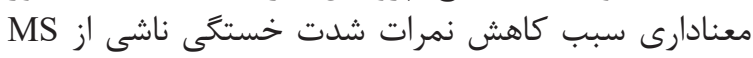

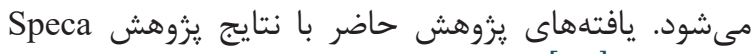

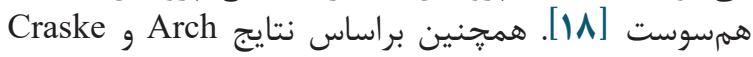

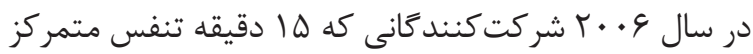

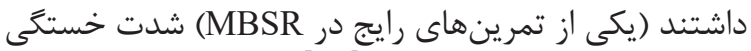

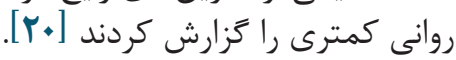

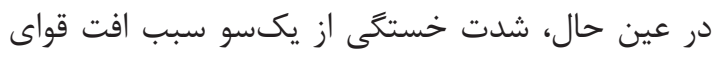

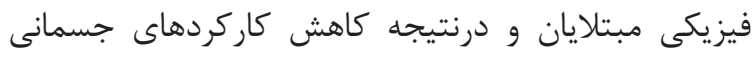

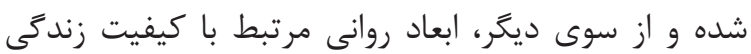

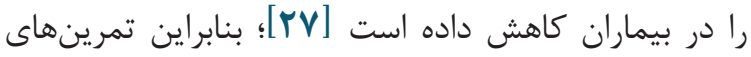

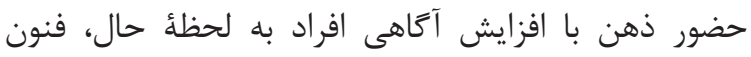

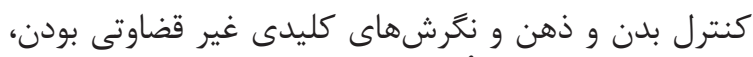

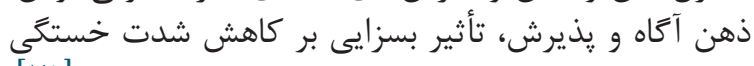

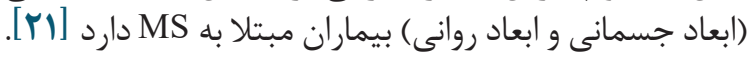

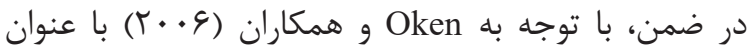

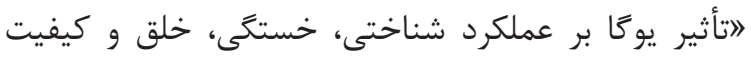

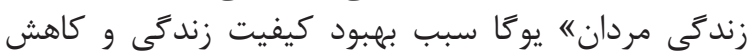

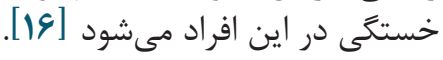

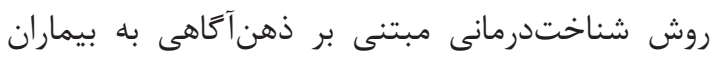

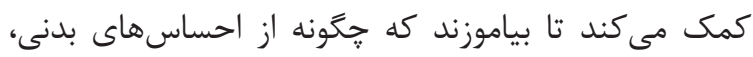

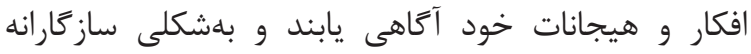

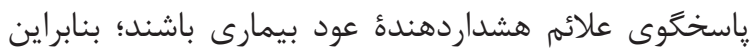

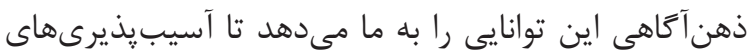

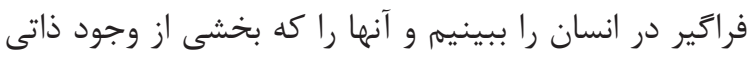

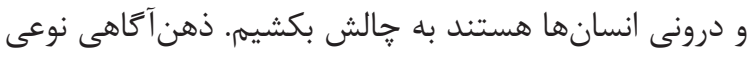

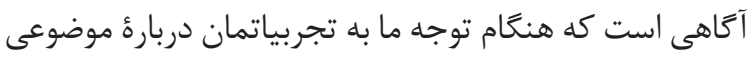

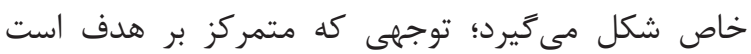

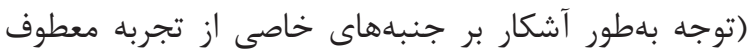

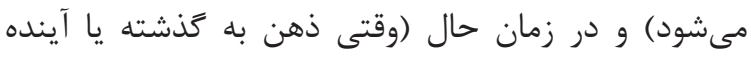




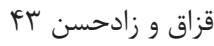

\section{References}

1. Salehpoor G, Rezaei S, Hosseininezhad M. Quality of life in Multiple Sclerosis (MS) and role of fatigue, depression, anxiety, and stress: A bicenter study from north of Iran. Iranian journal of nursing and midwifery research. 2014; 19(6):593.

2. Golan D, Doniger GM, Wissemann K, Zarif M, Bumstead B, Buhse M, et al. The impact of subjective cognitive fatigue and depression on cognitive function in patients with multiple sclerosis. Multiple Sclerosis Journal. 2018; 24(2):196-204. https://doi.org/10.1177/1352458517695470

3. Mao P, Reddy PH. Is Multiple Sclerosis A Mitochondrial Disease. Biochimica et Biophysica Acta (BBA)-Molecular Basis of Disease. 2010; 1802(1):66-79. https://doi.org/10.1016/j.bbadis.2009.07.002

4. Pakpour AH, Yekaninejad MS, Mohammadi NK, Molsted S, Zarei F, Patti F, et al. Health-related quality of life in Iranian patients with multiple sclerosis: a cross-cultural study. Neurology and Neurosurgery of Poland. 2009; 43(6):517-26.

5. Pugliatti M, Rosati G, Carton H, Riise T, Drulovic J, Vécsei L, et al. The epidemiology of multiple sclerosis in Europe. European journal of Neurology. 2006; 13(7):700-722. https://doi. org/10.1111/j.1468-1331.2006.01342.x

6. Kargarfard M, Eetemadifar M, Mehrabi M, Maghzi AH, Hayatbakhsh MR. Fatigue, depression, and health-related quality of life in patients with multiple sclerosis in Isfahan, Iran. European journal of neurology. 2012;19(3):431-437. https:// doi.org/10.1111/j.1468-1331.2011.03535.x

7. Allahbakhshian M, Jaffarpour M, Parvizy S, Haghani H. A Survey on relationship between spiritual wellbeing and quality of life in multiple sclerosis patients. Zahedan Journal of Research in Medical Sciences. 2010; 12(3):29-33.

8. Russell CS, White MB, White CP. Why me? Why now? Why multiple sclerosis?: Making meaning and perceived quality of life in a Midwestern sample of patients with multiple sclerosis. Families, Systems, \& Health. 2006; 24(1):65.

9. Siegert RJ, Abernethy DA. Depression in multiple sclerosis: A review. Journal of Neurology, Neurosurgery \& Psychiatry. 2005; 76(4):469475. https://doi.org/10.1136/jnnp.2004.054635

10. Benedict RH, Wahlig E, Bakshi R, Fishman I, Munschauer F, Zivadinov R, et al. Predicting quality of life in multiple sclerosis: accounting for physical disability, fatigue, cognition, mood disorder, personality, and behavior change. Journal of the neurological sciences. 2005; 231(1):2934. https://doi.org/10.1016/j.jns.2004.12.009
11. Ghafari S, Ahmadi F, Nabavi M, Anoshirvan K, Memarian R, Rafatbakhsh M. Effectiveness of applying progressive muscle relaxation technique on quality of life of patients with multiple sclerosis. Journal of clinical nursing. 2009; 18(15):2171-2179. https://doi.org/10.1111/ j.1365-2702.2009.02787.x

12. Crayton H, Heyman RA, Rossman HS. A multimodal approach to managing the symptoms of multiple sclerosis. Neurology. 2004; 63(11 suppl 5):S12-S18. https://doi.org/10.1212/ WNL.63.11_suppl_5.S12

13. Jean VM, Beatty WW, Paul RH, Mullins L. Coping with general and disease-related stressors by patients with multiple sclerosis: Relationships to psychological distress. Multiple Sclerosis Journal. 1997; 3(3):191-196. https://doi. org/10.1177/135245859700300304

14. Buchanan RJ, Schiffer R, Stuifbergen A, Zhu L, Wang S, Chakravorty BJ, Kim M. Demographic and disease characteristics of people with multiple sclerosis living in urban and rural areas. International Journal of MS Care. 2006; 8(3):89-97. https://doi.org/10.7224/1537-2073-8.3.89

15. Cakit BD, Nacir B, Genç H, Saraçoglu M, Karagöz A, Erdem HR, et al. Cycling progressive resistance training for people with multiple sclerosis: a randomized controlled study. American journal of physical medicine \& rehabilitation. 2010; 89(6):446-457. https://doi.org/10.1097/ PHM.0b013e3181d3e71f

16. Oken BS, Zajdel D, Kishiyama S, Flegal K, Dehen $\mathrm{C}$, Haas $\mathrm{M}$, et al. Randomized, controlled, six-month trial of yoga in healthy seniors: effects on cognition and quality of life. Alternative therapies in health and medicine. 2006; 12(1):40.

17. Imel Z, Baldwin S, Bonus K, MacCoon D. Beyond the individual: Group effects in mindfulness-based stress reduction. Psychotherapy Research. 2008; 18(6):735-742. https://doi. org/10.1080/10503300802326038

18. Speca M, Carlson LE, Goodey E, Angen M. A randomized, wait-list controlled clinical trial: the effect of a mindfulness meditation-based stress reduction program on mood and symptoms of stress in cancer outpatients. Psychosomatic medicine. 2000; 62(5):613-622. https://doi. org/10.1097/00006842-200009000-00004

19. Bogosian A, Chadwick P, Windgassen S, Norton S, McCrone P, Mosweu I, et al. Distress improves after mindfulness training for progressive MS: A pilot randomised trial. Multiple Sclerosis Journal. 2015; 21(9):1184-1194. https://doi. org/10.1177/1352458515576261 
20. Aghabagheri H, Mohammadkhani P, Omrani S, Farahmand V. The efficacy of mindfulness-based cognitive therapy group on the increase of subjective well-being and hope in patients with multiple sclerosis. Journal of clinical psychology. 2012; 1(13):23-31.

21. Blankespoor RJ, Schellekens MP, Vos SH, Speckens AE, de Jong BA. The effectiveness of mindfulness-based stress reduction on psychological distress and cognitive functioning in patients with multiple sclerosis: a pilot study. Mindfulness. 2017; 8(5):1251-1258. https://doi. org/10.1007/s12671-017-0701-6

22. Kabat-Zinn J. Mindfulness-based interventions in context: past, present, and future. Clinical psychology: Science and practice. $2003 ; 10(2): 144$ 156.

23. Brantley J. Mindfulness-based stress reduction. In Acceptance and mindfulness-based approaches to anxiety 2005 (pp. 131-145). Boston, MA: Springer. https://doi.org/10.1007/0-387-2598995

24. Teasdale JD, Segal ZV, Williams JM, Ridgeway VA, Soulsby JM, Lau MA. Prevention of relapse/recurrence in major depression by mindfulness-based cognitive therapy. Journal of consulting and clinical psychology. 2000; 68(4):615. https://doi.org/10.1037//0022-006X.68.4.615

25. Peterson LG, Pbert L. Effectiveness of a meditation-based stress reduction program in the treatment of anxiety disorders. American Journal of Psychiatry. 1992; 149(7):936-943. https://doi. org/10.1176/ajp.149.7.936

26. Baer RA, Krietemeyer J. Overview of mindfulness-and acceptance-based treatment approaches. Mindfulness-based treatment approaches: Clinician's guide to evidence base and applica-
FF أربخشى برنامئ كاهش استرس مبتنى بر ذهن آكاهى ..

tions. 2006:3-27. https://doi.org/10.1016/B978$\underline{012088519-0 / 50002-2}$

27. Shahvarvqy-Farahani A, Zymyan M, Fallah-Pour M. Reliability measures of the Persian versionof fatigue in people with MS. Rehabilitation. 2009; 10(4):46-51.

28. Brunner LS. Brunner \& Suddarth's textbook of medical-surgical nursing. Lippincott Williams \& Wilkins; 2010.

29. Brown KW, Ryan RM. The benefits of being present: mindfulness and its role in psychological well-being. Journal of personality and social psychology. 2003; 84(4):822.

30. Teasdale JD, Segal ZV, Williams JM. Mindfulness training and problem formulation. Clinical psychology: Science and practice. 2003; 10(2):157-160. https://doi.org/10.1093/clipsy/ bpg017

31. Baer RA, editor. Mindfulness-based treatment approaches: Clinician's guide to evidence base and applications. Elsevier; 2015.

32. da Silva AM, Vilhena E, Lopes A, Santos E, Gonçalves MA, Pinto C, et al. Depression and anxiety in a Portuguese MS population: associations with physical disability and severity of disease. Journal of the neurological sciences. 2011; 306(1):66-70. https://doi.org/10.1016/j. jns.2011.03.042 